\title{
Pattern of Presentation and Management of the Empty Scrotum In Children: A Ten Year Review At A Southwestern Tertiary Hospital In Nigeria
}

\author{
Nwokoro Cc ${ }^{1}$, Salami B.A ${ }^{1}$, Fatungase O.M ${ }^{2}$, Tade O.A ${ }^{1}$, Shonubi A M O ${ }^{1}$ \\ 1) Department Of Surgery \\ 2) Department Of Anaesthesia \& Intensive Care, \\ Olabisi Onabanjo University Teaching Hospital, Sagamu
}

\begin{abstract}
:
BACKGROUND: Absence of the testis in the scrotum is a common paediatric surgical disorder seen in our practice.
\end{abstract}

OBJECTIVE: To examine the presentation and treatment of the empty scrotum and postulate on the aetiology of the condition.

DESIGN: A ten year retrospective study (September 1998 - August 2008).

SETTING: Olabisi Onabanjo University Teaching Hospital, Sagamu.

METHODOLOGY: Case notes of children managed for empty scrotum during the study period were retrieved from the medical record department of the hospital. Data obtained included age of patient, at presentation, age at surgery, side of scrotum affected, investigations carried out, type of surgery done and outcome of treatment within 6 months of follow-up period. The data obtained were presented in tables and figures.

RESULTS: A total of 86 children were managed for empty scrotum during the study period. In 30 (34.9\%) patients, the condition was discovered at birth while in $56(65.1 \%)$ children it was discovered during early childhood period. Age range was 1-12 years with a median of 4 years. 36 (41.9\%) presented within the age of 2 years while 50 (58.1\%) cases presented above 2 years. The scrotum was empty on the right side only in 49 (57\%) cases, on the left side in 26 (30.2\%) patients. The scrotum was empty bilaterally in 11 (12.8\%) patients.

Undescended testes accounted for 68 (79.1\%), retractile testis occurred in $14(16.3 \%)$ and 4 (4.7\%) were iatrogenic. Investigations carried out in all the patients included full blood count, haemoglobin genotype, urinalysis and electrolytes, urea and creatinine assay. Groin exploration and orchidopexy was done in 72 (83.7\%) patients; of which 13 (18.1\%) had surgery at the age of 2 years; while surgery was done in 15 (20.8\%) patients at 3 years. Forty-four (61.1\%) of the treated patients had groin examination above 3 years of age.

Only 40 (55.6\%) of the operated cases were seen during the six months follow-up period. In 31 (77.5\%) of the patients seen during follow-up, the testes were of normal volume and consistency while in 9 (22.5\%) of the patients, the testes had shown significant reduction in volume when compared with the contralateral normal side. No death was recorded.

CONCLUSION: The study showed that most of the children presented late ( $>2$ years) for consultation at the hospital. Inferentially, empty scrotum was caused mostly by undescended testes. Greater numbers of patients may obtain normal testes after treatment if they reported earlier to the hospital.

\section{Introduction}

The testes are paired male gonads that produce spermatozoa and hormones.

By the 35 th week of gestation they descend from the pelvic region into the scrotum where they function optimally at $3-4^{\circ} \mathrm{C}$ below core body temperature.

The Scrotum is empty when the testes are absent, and described by the term cryptorchidism. This may result from incomplete descent of the testes ${ }^{1}$ into the scrotum; in which case they may be located at any point along the normal path of descent. Cryptorchidism may also arise from maldescent of testes ${ }^{2}$ when they become located at an ectopic site consequent on malformation of the gubernculum testis that guides the gonadal descent. It is notable that the gonads in both sexes develop in the lumbar region of the foetus and then descend to the level of internal inguinal ring. Further migration into the scrotum is influenced by androgens and Mullerian inhibiting substance (MIS), and therefore happens only in male fetuses. ${ }^{3}$

Cryptorchidism is present in about $4.5 \%$ of newborns with a higher incidence in preterms ${ }^{4,5,6}$. A testis located in the inguinal canal or abdomen is exposed continuously to $35^{\circ} \mathrm{C}$ and $37^{\circ} \mathrm{C}$ respectively with consequent progressive alteration in morphology and physiologic functions as well as an increased risk of complication $^{5}$. At age 2 years, a testis residing outside the scrotum and in the high temperature zones in the 
abdomen or inguinal canal would start to deteriorate. Early surgical correction helps to avert this and reduce the risk of complication. ${ }^{4,5}$

\section{Patients And Methods}

Case notes of children managed for empty scrotum during the study period were retrieved from the medical records department. Data obtain included age of at presentation, age at surgery, side of scrotum affected, investigations carried out, type of surgery done and outcome of treatment within 6 months of follow-up period. The data obtained were presented in tables and figures.

\section{Result}

A total of 86 children were managed for empty scrotum during the study period. In $30(34.9 \%)$ patients, the condition was discovered at birth while in $56(65.1 \%)$ children it was discovered during early childhood period. Age range of children studied was 1-12 years with a median of 4 years. Age at presentation of empty scrotum is given in Table 1. As shown in Table 2, the scrotum was empty on the right side only in $49(57 \%)$ cases, on the left side in $26(30.2 \%)$ patients, and bilaterally in $11(12.8 \%)$ children. Undescended testes accounted for $68(79.1 \%)$, retractile testis occurred in $14(16.2 \%)$ and $4(4.7 \%)$ were iatrogenic. Table 3 shows the age at which surgical intervention of groin exploration and orchidopexy was done in $72(83.7 \%)$, however those with retractile testes $14(17.3 \%)$ were not given further treatment.

Only $40(46.5 \%)$ of the operated cases were seen during the 6-months follow-up period. However, out of $31(77.5 \%)$ of the patients seen during follow-up, the testes were of normal volume and consistency while in $9(22.5 \%)$ of the patients, the testes had shown significant reduction in volume when compared with the contralateral normal side. Investigations carried out in all the patients included full blood count, haemoglobin genotype, urinalysis and electrolytes, urea and creatinine assay. No death was recorded among the children studied.

TABLE 1

AGE OF CHILDREN WITH EMPTY SCROTUM IN STUDY

\begin{tabular}{|c|c|c|}
\hline AGE RANGE (YEARS) & NUMBER OF CHILDREN & PERCENTAGE \% \\
\hline $0-2$ & 36 & 41.9 \\
\hline$>2$ & 50 & 58.1 \\
\hline TOTAL & 86 & 100.0 \\
\hline
\end{tabular}

TABLE 2

SIDENESS OF EMPTY SCROTUM IN CHILDREN STUDIED

\begin{tabular}{|c|c|c|}
\hline SIDE OF BODY & NUMBER OF CHILDREN & PERCENTAGE \% \\
\hline UNILATERAL LEFT & 26 & 30.2 \\
\hline UNILATERALRIGHT & 49 & 57.0 \\
\hline BILATERAL & 11 & 12.8 \\
\hline TOTAL & 86 & 100.0 \\
\hline
\end{tabular}

TABLE 3

AGE AT SURGICAL INTERVENTION IN CHILDREN WITH EMPTY SCROTUM STUDIED

\begin{tabular}{|c|c|c|}
\hline AGE (YEARS) & NUMBER OF CHILDREN & PERCENTAGE \% \\
\hline 2 & 13 & 18.1 \\
\hline 3 & 15 & 20.8 \\
\hline 4 & 31 & 43.1 \\
\hline 5 & 7 & 9.7 \\
\hline TOTAL & 6 & $\mathbf{8 . 3}$ \\
\hline
\end{tabular}

\section{Discussion}

Cryptorchidism literally means hidden or obscure testis. It is characteristic of males with incomplete testicular descent ${ }^{7}$ or maldescent of the gonads ${ }^{8}$. The condition may be unilateral or bilateral. The term encompasses palpable, non-palpable, and ectopic testicles The position of testis can be abdominal, inguinal, prescrotal, or ectopic. Incidence is $3-5 \%$ in full term boys, and $1.8 \%$ at one year of age. The testicles descend to a scrotal position in human beings in order to optimize sperm production ${ }^{4}$.

The actual mechanism of gonadal descent is not exactly known at present time. Certain important factors that cause proper descent include traction on testis by attachments in the scrotum, differential growth of the body wall, intra-abdominal pressure, maturation of the epididymis and multiple hormonal factors ${ }^{9}$.

When the testicle doesn't descend, surgery is recommended by the first year of life. Data obtained in this study showed that it was possible to surgically place the testes in the scrotum in 72 children. This indicates 
that the commonest cause of empty scrotum was undescended testis, because in maldescended testis the gubernaculum testis and/or inguinal canal is malformed making it impossible to draw the gonads into the scrotum.

In 30 patients, the condition was discovered at birth while in 56 it was discovered during early childhood period. That most of the patients, $50(58.1 \%)$ presented above the age of 2 years is of notable concern. This is later than indicated from the reports of studies carried out in advanced countries ${ }^{10,11}$. In the developed countries high level of awareness corresponds with early patient presentation and intervention. The present report appears to support the deduction that in developing countries, patients present late as a result of ignorance. $^{6}$

The sideness of empty scrotum being reported in this study agrees with findings of authors from other centres $^{12,13}$. Undescended testes was the commonest cause of the empty scrotum followed by retractile testes. Whereas the actual cause of undescended testes is unknown, a number of pre-disposing factors are documented: Included are prematurity, Low birth weight, Small for gestational age, Twinning, and maternal exposure to estrogen during the first trimester. ${ }^{14}$

It is postulated that testicular descent involves differential body growth relative to spermatic cord/gubernaculum, increased intra-abdominal pressure, hormonal factors including testosterone and extrinsic estrogen; development and maturation of the epididymis and gubernacular attachment ${ }^{9}$.

Usually no other symptoms may be present other than inability to find the testicle in the scrotum, but in adults infertility may be reported due to undescended testis. Problems associated with undescended testis includes the following: Infertility, inguinal hernia, tumor of the testis, cosmetic and psychological problems, Injury of the undescended testis and torsion or twisting of the testis ${ }^{5,6}$. In order to avoid these complications, surgery is advised between 1 to 2 years of age $e^{15,16}$.

In our study, groin exploration and orchidopexcy were carried out in $72(83.7 \%)$ patients included in the study while $14(16.3 \%)$ patients with retractile testis had no further treatment. The age at surgery was influenced by the time of presentation. Overall, most of the patients had surgery after the age of 2 years. This contrasts what pertains in advanced countries where surgeries are routinely carried out before the age of 2 years to avert the untoward effects of the absence of the testes in the scrotum ${ }^{4,5}$.

\section{Conclusion}

Children with empty scrotum presented late to our hospital hence, most of the children were operated after the age of 2 years. Nonetheless, majority $(77.5 \%)$ of the children who received surgical intervention showed normal testis at 6 months follow-up; suggesting that better treatment results may be obtained if the patients reported before age two.

\section{Acknowledgment}

We wish to acknowledge the efforts and contributions of Dr. G.A. Sule of the Department of Surgery.

\section{References}

[1]. Scorer CG, The Anatomy of testicular descent-normal and incomplete. BJS 1961; 49:357-364

[2]. Mike O, Harish C, Maldescent of the testes. Surgery 2005;23:335-338

[3]. Heath Al, Man DW, Eckstein HB. Factors controlling descent. Epididymal abnormalities associated with maldescent of the testis. J Pediatr surg 1984;19:47-49

[4]. Umakanth A. Khatwa, Menon P. S. N. Management of undescended testis. Indian Journal of Pediatrics. 2000;67:449-454

[5]. Williams EV, Appanna T, Foster ME. Management of the impalpable testis: a six year review together with a national experience. Postgrad Med J 2001;77:320-322

[6]. Osifo OD, Evbuomwan I. Undescended testes in a developing country: A study of the management of 71 patients. African Journal of Pediatric Surgery 2008;5:11-14.

[7]. Huston JM, Balic A, Nation T, Southwell B. Cryptordirdism. Semin pediatr surg 2010;19:215-224

[8]. Spitz L. Maldescent of the testis. Arch Dis child 1983;58:847-848

[9]. Ieuan AH, Carlo LA. Factors controlling testis descent. European Journal of endocino Legy, 2008;159:75-82

[10]. Schindler AM, Diaz P, Cuendet A, Sizonenko PC. Cryptorchidism: a morphological study of 670 biopsies. Helv Paediatr Acta. 1987;42:145-58.

[11]. Mantovani F, Cazzaniga A, Mastromarino G, Colombo F, Austoni E. Early diagnosis and correct treatment of cryptorchism. Arch Ital Urol Nefrol Androl. 1991;63:403-8.

[12]. Mlay SM, Sayi EN. Undescended testis in paediatric patients at Muhimbili Medical Centre, Dar es Salaam. East Afr Med J. $1994 ; 71: 135-7$.

[13]. Zucchini S, Tacconi M, Cacciari E. Cryptorchidism. Pediatr Med Chir. 1992;14:369-74.

[14]. Ayla K, Ibrahim O, Can P, Ragiba Z, Mustapha AT. Undescended testis: its anatomical localization and aetiological factors. Int j of Urol Nurs 2013;7:17-24

[15]. Steven GD, Richard IS, William C. The undescended Testicle: Diagnosis and Management. Am Fam Physician. 2000;62:2037-2044

[16]. AMEH E.A, MBIBU H.N. Management of undescended testis in children in Zaria, Nigeria. East African Medical Journal $2000 ; 77: 485-487$ 